OPEN ACCESS

Edited by:

Zisis Kozlakidis,

International Agency For Research On

Cancer (IARC), France

Reviewed by:

llias Papanikolaou,

General Hospital of Corfu, Greece

Bugra Kerget,

Atatürk University, Turkey

*Correspondence:

Johanna Sjöwall

johanna.sjowall@liu.se

Specialty section:

This article was submitted to Infectious Diseases - Surveillance,

Prevention and Treatment,

a section of the journal

Frontiers in Medicine

Received: 08 October 2021 Accepted: 12 November 2021

Published: 02 December 2021

Citation:

Enocsson $H$, Idoff C, Gustafsson A, Govender M, Hopkins F, Larsson M Nilsdotter-Augustinsson $\AA$ and

Sjöwall J (2021) Soluble Urokinase Plasminogen Activator Receptor

(suPAR) Independently Predicts Severity and Length of Hospitalisation in Patients With COVID-19. Front. Med. 8:791716.

doi: 10.3389/fmed.2021.791716

\section{Soluble Urokinase Plasminogen Activator Receptor (suPAR) Independently Predicts Severity and Length of Hospitalisation in Patients With COVID-19}

\author{
Helena Enocsson ${ }^{1}$, Cornelia Idoff ${ }^{1}$, Annette Gustafsson ${ }^{2}$, Melissa Govender ${ }^{3}$, \\ Francis Hopkins $^{3}$, Marie Larsson ${ }^{3}$, Åsa Nilsdotter-Augustinsson ${ }^{1}$ and Johanna Sjöwall ${ }^{1,2 \star}$ \\ 'Division of Inflammation and Infection, Department of Biomedical and Clinical Sciences, Linköping University, Linköping, \\ Sweden, ${ }^{2}$ Department of Infectious Diseases, The Vrinnevi Hospital, Norrköping, Sweden, ${ }^{3}$ Division of Molecular Medicine \\ and Virology, Department of Biomedical and Clinical Sciences, Linköping University, Linköping, Sweden
}

Background: Efficient healthcare based on prognostic variables in hospitalised patients with COVID-19 could reduce the risk of complications and death. Recently, soluble urokinase Plasminogen Activator Receptor (SuPAR) was shown to predict respiratory failure, kidney injury, and clinical outcome in patients with SARS-CoV-2 infection. The aim of this study was to investigate the value of suPAR as a prognostic tool, in comparison with other variables, regarding disease severity and length of hospital stay in patients with COVID-19.

Patients and Methods: Individuals hospitalised with COVID-19 (40 males, 20 females; median age 57.5 years) with a median symptom duration of 10 days and matched, healthy controls $(n=30)$ were included. Admission levels of suPAR were measured in serum by enzyme-linked immunosorbent assay. Blood cell counts, C-reactive protein (CRP) levels, lactate dehydrogenase $(\mathrm{LDH})$, plasma creatinine and estimated glomerular filtration rates were analysed and oxygen demand, level of care and length of hospitalisation recorded.

Results: Patients had significantly higher suPAR levels compared to controls $(P<$ 0.001). Levels were higher in severely/critically (median $6.6 \mathrm{ng} / \mathrm{mL}$ ) compared with moderately ill patients (median $5.0 \mathrm{ng} / \mathrm{mL} ; P=0.002$ ). In addition, suPAR levels correlated with length of hospitalisation (rho $=0.35 ; P=0.006$ ). Besides suPAR, LDH, CRP, neutrophil count, neutrophil-to-monocyte and neutrophil-to-lymphocyte ratio, body mass index and chronic renal failure were discriminators of COVID-19 severity and/or predictors of length of hospitalisation.

Conclusion: Admission levels of suPAR were higher in patients who developed severe/critical COVID-19 and associated with length of hospital stay. In addition, we showed that suPAR functioned as an independent predictor of COVID-19 disease severity.

Keywords: SuPAR, COVID-19, biomarker, disease severity, respiratory failure, length of hospital stay 


\section{INTRODUCTION}

The ongoing pandemic caused by the novel severe acute respiratory syndrome coronavirus 2 (SARS-CoV-2) has caused extensive morbidity and deaths, which has entailed an enormous burden on the healthcare system worldwide. The SARS-CoV-2 can cause an asymptomatic to severe coronavirus disease 2019 (COVID-19), and when severe has serious impact primarily on the lungs, but also on several other organs (1-3). Pneumonia with subsequent respiratory failure may develop already within the first week after disease onset (4-6), leading to hospitalisation of patients in need of oxygen supplementation or with multiple organ dysfunction. At this stage of the infection, it is difficult to predict which patients will need intensified oxygen supplementation, either as high-flow nasal oxygen therapy (HFNOT), continuous positive airway pressure (CPAP) therapy, or mechanical ventilation, and to estimate the length of hospital stay. Prognostic markers are essential for identifying patients at risk of developing severe COVID-19, so that appropriate care interventions can be offered prophylactically or at least at an early stage of the disease. Certain blood-based biomarkers, such as lymphocyte, neutrophil and platelet counts, neutrophil-tomonocyte ratio (NMR), neutrophil-to-lymphocyte ratio (NLR), D-dimer, interleukin-6, C-reactive protein (CRP) levels and lactate dehydrogenase (LDH) may discriminate between severe and non-severe COVID-19 $(4,7,8)$. Another biomarker, the soluble urokinase plasminogen activator receptor (suPAR), has been shown to be significantly elevated in patients with COVID19 (9), and stands out as a predictor of overall disease severity and outcome (10-15) and in particular of severe respiratory failure (16), and acute kidney injury (17) due to SARS-CoV-2 infection.

The cell-bound urokinase-type plasminogen activator receptor (UPAR) is found on various cell types such as endothelial cells and activated neutrophils and is upregulated at sites of inflammation and tissue remodelling $(18,19)$. Apart from urokinase plasminogen activator (uPA, also known as urokinase), uPAR interacts and cooperates with many ligands and receptors, primarily integrins, to facilitate intracellular signalling, cell migration, cell adhesion and tissue remodelling (20). Soluble uPAR (suPAR) results from proteolytic cleavage of uPAR (21), and has gained increased interest as circulating levels are found to reflect severity and prognosticate outcome of several malignant (22-26), autoimmune (27-30) and infectious diseases (31-37). Additionally, suPAR is used in triaging of patients in acute care settings to early predict clinical deterioration due to suspected bacterial infections (38-42).

As suPAR has only recently been suggested to predict the outcome of COVID-19, and its significance in hospitalised patients with different disease severity is not yet fully understood, we conducted this prospective cohort study with the aim to

Abbreviations: suPAR, soluble urokinase plasminogen activator; NMR, neutrophil-to-monocyte ratio; NLR, neutrophil-to-lymphocyte ratio; LDH, lactate dehydrogenase; CRF, chronic renal failure; CRP, C-reactive protein; BMI, body mass index; CVD, cardiovascular disease; HFNOT, high-flow nasal oxygen therapy; CPAP, continuous positive airway pressure; eGFR, estimated glomerular filtration rate. evaluate whether suPAR, in comparison to established bloodbased immune mediators, may prognosticate respiratory failure and length of hospital stay in adult patients with SARS-CoV2 infection.

\section{MATERIALS AND METHODS \\ Study Design and Participants}

This study was part of a prospective, observational cohort study, implemented during August 2020 to May 2021, involving consecutive adult patients with COVID-19, who were assessed for their eligibility of inclusion as soon as possible following admittance to the Department of Infectious Diseases at the Vrinnevi Hospital, Norrköping, Sweden. Inclusion criteria were age $>18$ years, ability to give informed consent and with a current diagnosis of COVID-19, as verified by Abbott Real Time SARS-CoV-2 or Alinity m SARS-CoV-2 assays (Abbott, Solna, Sweden) using nasopharyngeal or throat swab specimens, performed at the Clinical Microbiology Laboratory, Linköping University Hospital, Sweden.

Healthy, SARS-CoV-2 RNA negative controls, verified by an in-house RealTime quantitative PCR performed as previously described (43), were matched to the patients regarding age and sex and were only used for comparison of suPAR levels. They consisted of health care workers at the Vrinnevi Hospital $(n=$ 17) and blood donors $(n=13)$ at the Department of Clinical Immunology and Transfusion medicine, Linköping University Hospital, Sweden.

\section{Clinical Characteristics of Patients, Disease Severity Classification and Biochemical Variables}

At inclusion, patients were asked by a questionnaire about the duration of COVID-19-associated symptoms and smoking habits. Digital medical records were reviewed with respect to various factors: presence of cardiovascular disease (CVD, including hypertension), chronic pulmonary disease (asthma, chronic obstructive pulmonary disease, pulmonary fibrosis or other chronic illnesses affecting the lungs), chronic renal failure (CRF), diabetes, current medication, date of confirmed SARS-CoV-2 infection, immunosuppression (disease and/or current medical treatment that suppress the immune system), length of hospital stay, highest level of care received, maximum need of oxygen supplementation $(<5 \mathrm{~L} / \mathrm{min}$ or HFNOT/CPAP/mechanical ventilation), need of renal dialysis, and lastly, COVID-19 related medication (anticoagulants, remdesivir and/or dexamethasone).

In the patient cohort of hospitalised patients, COVID-19 severity was classified according to the National Institute of Health (44) and approximated with respect to the highest level of care (pandemic department, intermediate or intensive care unit) and the maximum oxygen need as mild (pandemic department, no oxygen supplementation), moderate (pandemic department, oxygen supplementation $<5 \mathrm{~L} / \mathrm{min}$ ), severe (pandemic department or intermediate care unit, oxygen need $\geq 5 \mathrm{~L} / \mathrm{min}$ supplemented by HFNOT or CPAP) and critical illness 
(intensive care unit, with or without mechanical ventilation). Because only a few patients were classified as mild and critical, respectively, two groups of disease severity (mild/moderate and severe/critical) were used in analyses throughout this study.

Patients were analysed for baseline haemoglobin, blood cell counts (platelets, leukocytes, monocytes, lymphocytes, neutrophils, eosinophils, and basophils), CRP, LDH, sodium, potassium and plasma creatinine at the Clinical Chemistry Unit, Vrinnevi Hospital, Norrköping. The estimated glomerular filtration rate (eGFR) was calculated using the MDRD 4-variable equation (45). An eGFR of $>90 \mathrm{~mL} / \mathrm{min} / 1,73 \mathrm{~m}^{2}$ was not further specified and was given the value of $100 \mathrm{~mL} / \mathrm{min} / 1,73 \mathrm{~m}^{2}$. Body mass index (BMI), the neutrophil-to-monocyte (NMR) and neutrophil-to-lymphocyte ratios (NLR) were calculated.

\section{SuPAR Analysis}

Serum from patients and controls was prepared from venous whole blood, drawn at study inclusion, and stored at $-80^{\circ} \mathrm{C}$ until analysis. Serum suPAR was measured in duplicates by the clinically validated suPARnostic ELISA kit (Virogates, Birkerød, Denmark) according to the manufacturer's instructions. In brief, samples, standards and controls were mixed with peroxidase conjugated anti-suPAR antibodies and thereafter transferred to a 96-well plate, precoated with anti-suPAR antibodies. After $1 \mathrm{~h}$ of incubation in room temperature and subsequent washing of the plate, 3', 3',5',5'-tetramethylbenzidine was added. The reaction was stopped after $20 \mathrm{~min}$ of incubation by the addition of sulphuric acid, and the absorbance was measured at $450 \mathrm{~nm}$ with $650 \mathrm{~nm}$ as reference wavelength, in an absorbance reader (SpectraMax ABS Plus from Molecular Devices, LCC, San Jose, CA, USA) and analysed using Softmax Pro 7 (Molecular Devices, LCC). The curve controls, accompanied with the ELISA kit, were within range in all assays. Serum samples with optical density values above the range of the standard curve were diluted 1:5 and re-run. The mean coefficient of variation between duplicates was $6.1 \%$ (range 0.1-25.8\%).

\section{Statistical Analysis}

suPAR was not normally distributed and hence, non-parametric tests were generally used. Mann-Whitney $U$-test was always used when two groups were compared, and Spearman's correlation was used for all correlation analyses. $\chi^{2}$ test with Fisher's exact method was used for categorical data. Kruskal Wallis with Dunn's multiple comparison was used when more than two groups were compared. For linear regression analysis, the dependent variable (length of hospital stay) was log-transformed prior to analysis to achieve a normal distribution. Values below limit of quantitation were given half the value of the limit. A two-sided $P$-value $\leq 0.05$ was considered significant. IBM SPSS Statistics, version 23 was used for statistical calculations. GraphPad Prism 9.1.2 software (GraphPad, La Jolla, CA, USA) was used for the graphical illustrations.

\section{Ethical Considerations}

Oral and written informed consent was obtained from all participants. The study protocol was approved by the Swedish Ethical Review Authority (Decision number 2020-02580).

\section{RESULTS}

\section{Characteristics of Patients and Controls}

Sixty hospitalised patients (40 males [67\%], median age 57.5 years [range 23-91]) with confirmed COVID-19 constituted the patient cohort. The median age among the controls was 56 years (range $31-69)$ and $66 \%(n=20)$ were males. Five individuals were above 75 years of age, as the very old patients to a large extent had confusion and or dementia or were unable to participate for other reasons.

Fifty-seven percent $(n=34)$ were ever smokers and $25 \%$ $(n=15)$ had chronic pulmonary disease. CVD, including hypertension, was present in $57 \%(n=34)$ of the patients, diabetes in $25 \%(n=15)$ and the median BMI was 30 (range 22-45). Seven (12\%) patients had CRF, whereof one received intermittent haemodialysis (Table 1). Acute renal failure (including those with acute on CRF) was observed in ten (17\%) patients at inclusion, and two needed continuous renal replacement therapy at the intensive care unit (Table 1). Eight (13\%) patients were considered immunocompromised, whereof one had acute myeloid leukaemia and another two multiple myeloma receiving cytostatic treatment, respectively, one had newly diagnosed chronic lymphatic leukaemia without active treatment, two had undergone kidney transplantation and were treated with cyclosporine and mycophenolate mofetil and two had spondyloarthritis receiving treatment with tumour necrosis factor inhibitors (adalimumab and etanercept, respectively) (Table 1). The median symptom duration at inclusion was 10 days (range 2-30) and the median length of hospital stay one week (2-54 days). The length of hospital stay was considered a surrogate measure of disease severity, and since the maximum length of stay in discharged patients was 54 days, the deceased patients were given a fictive stay of 55 days to avoid bias. All patients received, according to current recommendations, anticoagulant therapy (low molecular weight heparin or continued with direct acting oral anticoagulants or warfarin) at admission to hospital. At study inclusion, 23 (38\%) patients received or had previously received the antiviral treatment remdesivir ( $200 \mathrm{mg}$ day 1 , followed by $100 \mathrm{mg}$ once daily for 5-10 days) and 38 (63\%) were prescribed either oral or intravenous dexamethasone (6 mg once daily for up to 10 days), betamethasone ( $4 \mathrm{mg}$ once daily for 5 days) or prednisolone (30 mg per day for 5 days) (Table $\mathbf{1}$ ).

Baseline blood cell counts, CRP levels, LDH, sodium, potassium, plasma creatinine, eGFR, BMI, NMR and NLR in the patient cohort are presented in Table $\mathbf{1}$.

\section{Classification of COVID-19 Severity}

COVID-19 severity was classified as mild in six (10\%), moderate in 25 (42\%), severe in 21 (35\%) and critical in 8 patients (13\%), of whom all eight needed intensive care (seven males, one female; median length of stay 9 days [1-24]), whereof four (7\%) males received mechanical ventilation (median 13.5 days, range 2-21). One of the critically ill, mechanically ventilated patients had a kidney transplant. Two (3\%) male patients needed continuous renal replacement therapy at the intensive care unit. Two male 
TABLE 1 | Clinical characteristics of and biochemical variables in the patient cohort.

\begin{tabular}{|c|c|}
\hline \multicolumn{2}{|l|}{ Patients, number $(n) 60$} \\
\hline Male sex, $n,(\%)$ & $40(67)$ \\
\hline Age, years median (range) & $57.5(23-91)$ \\
\hline Current or ex-smoker, $n(\%)$ & $34(57)$ \\
\hline Cardiovascular disease, $n(\%)$ & $34(57)$ \\
\hline Chronic pulmonary disease, $n(\%)$ & $15(25)$ \\
\hline Acute renal failure, $n(\%)$ & $10(17)$ \\
\hline Chronic renal failure, $n(\%)$ & $7(12)$ \\
\hline Renal replacement therapy, $n$ (\%) & $3(5)$ \\
\hline Diabetes, $n(\%)$ & $15(25)$ \\
\hline Body mass index $\left(\mathrm{kg} / \mathrm{m}^{2}\right)$, median (range) & $30(22-45)$ \\
\hline Immunocompromised ${ }^{\#}$ at inclusion, $n(\%)$ & $8(13)$ \\
\hline Symptom duration, days median (range) & $10(2-30)$ \\
\hline Length of hospital stay, days median (range) & $7(2-54)$ \\
\hline Deceased, $n(\%)$ & $2(3)$ \\
\hline \multicolumn{2}{|l|}{ COVID-19 severity: } \\
\hline Mild, $n(\%)$ & $6(10)$ \\
\hline Moderate & $25(42)$ \\
\hline Severe, $n(\%)$ & $21(35)$ \\
\hline Critical, $n(\%)$ & $8(13)$ \\
\hline Mechanical ventilation, $n(\%)$ & $4(7)$ \\
\hline Mechanical ventilation, days median (range) & $13.5(2-21)$ \\
\hline Intensive care, $n(\%)$ & $8(13)$ \\
\hline Stay at intensive care unit, days median (range) & $9(1-24)$ \\
\hline Anticoagulants, $n(\%)$ & $60(100)$ \\
\hline Remdesivir, $n(\%)$ & $23(38)$ \\
\hline Corticosteroid therapy, $n$ (\%) & $38(63)$ \\
\hline \multicolumn{2}{|l|}{ Biochemical variables at inclusion: } \\
\hline Haemoglobin g/L, median (range) & $127(87-171)$ \\
\hline White blood cell count ( $\left.\times 10^{9} / \mathrm{L}\right)$, median (range) & $6.7(0.4-47)$ \\
\hline Platelet count (x 109/L), median (range) & $240(20-668)$ \\
\hline Neutrophil count (x 109/L), median (range) & $5.0(0.1-17.5)$ \\
\hline Lymphocyte count (x 109/L), median (range) & $1.0(0.1-33)$ \\
\hline NLR, median (range) & $4.9(0.2-88)$ \\
\hline NMR, median (range) & $13.1(4.0-180)$ \\
\hline C-reactive protein (mg/L), median (range) & $62.5(6-477)$ \\
\hline Sodium (mmol/L), median (range) & $138(128-144)$ \\
\hline Potassium (mmol/L), median (range) & $3.9(3.2-4.8)$ \\
\hline Plasma creatinine ( $\mu \mathrm{mol} / L)$, median (range) & $69.5(36-1224)$ \\
\hline eGFR MDRD (mL/min/1.73m²), median (range) & $69(4->90)$ \\
\hline Lactate dehydrogenase ( $\mu$ kat/L), median (range) & $6.5(3.2-16)$ \\
\hline
\end{tabular}

\# Disease and/or current medical treatment that suppress the immune system, such as haematological or other malignancy, rheumatic disease, and organ transplantation. HFNOT, high flow nasal oxygen therapy; eGFR, estimated glomerular filtration rate; NLR, neutrophil-to-lymphocyte ratio; NMR, neutrophil-to-lymphocyte ratio. Disease severity was classified according to the National Institute of Health and approximated with respect to maximum oxygen need as mild (pandemic department, no oxygen supplementation), moderate (pandemic department, oxygen supplementation $<5 \mathrm{~L} / \mathrm{min}$ ), severe (pandemic department or intermediate care unit, oxygen need $\geq 5 \mathrm{~L} /$ min supplemented by high-flow nasal oxygen therapy or continuous positive airway pressure therapy) and critical illness (intensive care unit, with or without mechanical ventilation). patients deceased during the hospital stay, whereof one had acute myeloid leukaemia and the other had CVD, obesity, and diabetes. The former patient was treated at an intermediate care unit ( 8 days) and the other received intensive care (22 days) with mechanical ventilation and continuous renal replacement therapy.

\section{SuPAR in Relation to Patient Characteristics and Biochemical Variables}

The COVID-19 patients had significantly higher baseline suPAR levels (median 5.9, IQR 4.8-7.9) compared to the matched controls (median 2.44, IQR 1.66-3.02, $P<0.001$; Figure 1A). Among patients, suPAR was correlated with age $(P>0.001$, rho $=0.42)$ and length of hospital stay $(P=0.006$, rho $=$ 0.35 ) but not with BMI, or symptom duration. Significantly higher suPAR levels were found among patients with CRF ( $P$ $<0.001)$ and CVD $(P=0.043)$ compared to patients without the respective disorders. Furthermore, patients treated with remdesivir had higher suPAR levels $(P=0.03)$ compared to patients without remdesivir. Higher suPAR levels were also found among patients with corticosteroid treatment $(P=0.006)$. For this reason, patients were also stratified based on CVD and/or CRF (Figure 1B), remdesivir treatment (Figure 1C) and corticosteroid treatment (Figure 1D) for comparison with the healthy controls. This analysis revealed that all patient subgroups had significantly higher suPAR levels in comparison with the healthy control group (Figures 1B-D).

No statistically significant differences in suPAR levels were found among the patients considering biological sex, smoking habits, immunosuppressive disorders, presence of chronic pulmonary disease, or diabetes.

Biochemical factors that correlated significantly with suPAR levels were plasma creatinine $(P=0.008$, rho $=0.34)$ and eGFR $(P=0.012$, rho $=-0.32)$. No correlation was found with CRP levels, LDH, haemoglobin, blood cell counts, NMR, NLR, or electrolytes.

\section{SuPAR, and Other Biochemical and Clinical Variables in Association With Length of Hospital Stay}

The length of hospitalisation significantly associated with suPAR levels $(P=0.006$, rho $=0.35)$, LDH $(P<0.001$, rho $=$ $0.55)$, lymphocyte count $(P=0.008$, rho $=-0.34)$, CRP $(P$ $=0.017$, rho $=0.31)$ and NLR $(P=0.030$, rho $=0.28)$ (Figures 2A-E), respectively. No correlation was found between length of hospital stay and other immune cell counts, sodium, potassium, plasma creatinine, or eGFR (not shown). Among the clinical variables, only CRF was significantly associated with length of hospital stay ( $P=0.002$; Figure 2F). Remdesivir treated patients had significantly longer hospital stay (median 8 days, range $3-54, P=0.004$ ), whereas no significant difference in length of hospital stay was found dependent on corticosteroid treatment. 
A

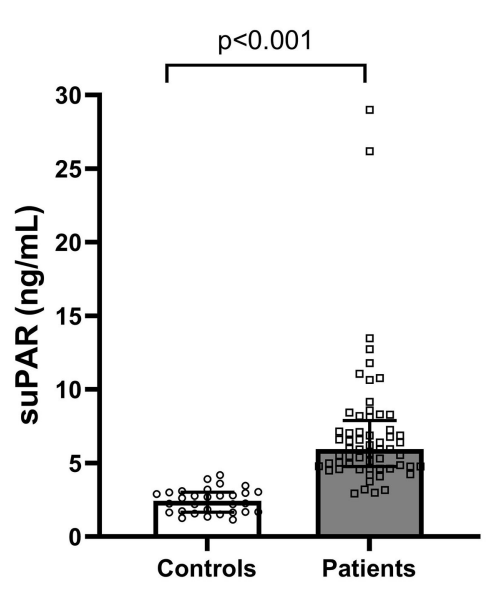

C

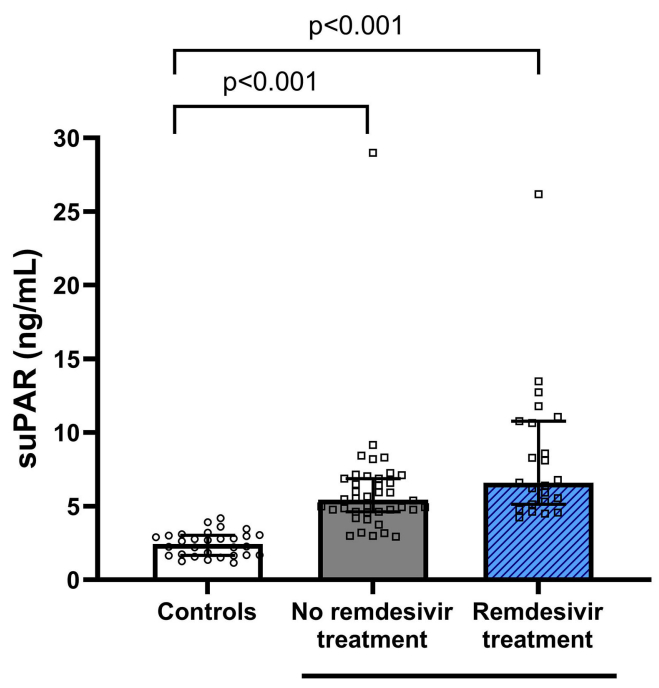

Patients
B

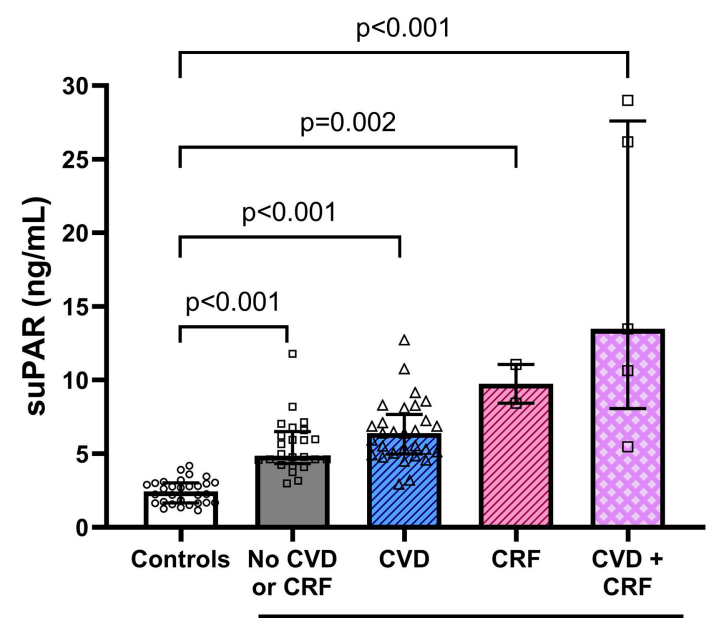

Patients

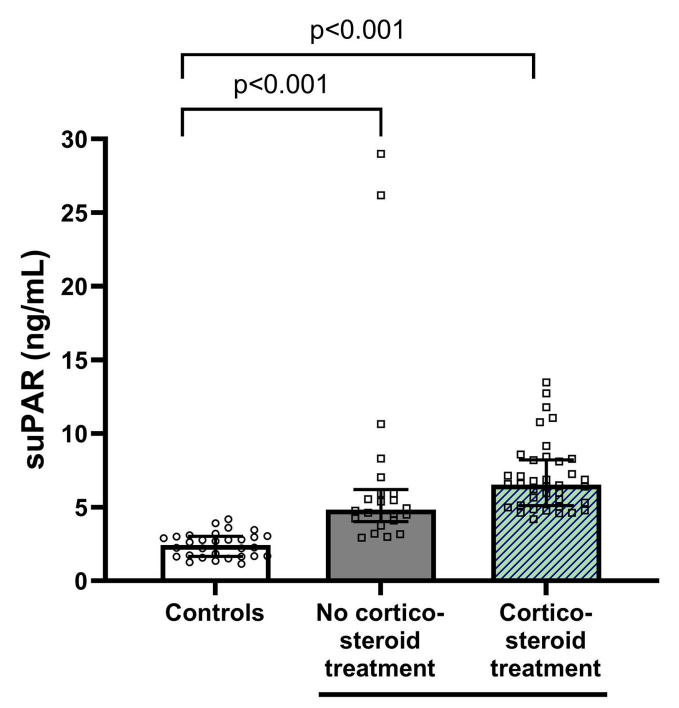

Patients

FIGURE 1 | Soluble urokinase plasminogen activator receptor (suPAR) levels in controls and patients hospitalised with COVID-19. suPAR serum concentration was compared between individuals hospitalised with COVID-19 and healthy age- and sex-matched controls (A). COVID-19 patients were also stratified based on comorbidities (B) and treatments (C,D) of importance for suPAR levels and thereafter compared with the control group. Bars and error bars show median and inter quartile range. Dots represent individual values. suPAR, soluble urokinase plasminogen activator receptor; CVD, cardiovascular disease; CRF, chronic renal failure.

\section{Predictors of Length of Hospital Stay in a Multiple Linear Regression}

A linear regression model with stepwise analysis revealed that none of the potential confounders (age, eGFR, corticosteroid and remdesivir treatment) abolished the association of suPAR with length of hospital stay $(P=0.004)$. Only remdesivir treatment remained significant $(P=0.007)$ in the regression model together with suPAR (not shown).

To create an optimised model for prediction of length of hospital stay, all biochemical variables ( $\mathrm{LDH}$, suPAR, lymphocyte count, CRP and NLR) that were significantly associated with this outcome variable were attested by linear regression. In the analysis including the lymphocyte count
(Table 2, Model 1), only suPAR $(P=0.001)$ remained an independent variable, whereas $\mathrm{LDH}$, lymphocyte count and CRP were excluded from the model (Table 2). A linear regression model with stepwise analysis of suPAR, NLR, LDH and CRP proved suPAR $(P=0.003)$ and NLR $(P=0.022)$ to be significantly associated with length of hospital stay, while LDH and CRP were excluded from the model (Table 2, Model 2).

Among clinical variables, $\mathrm{CRF}$ and remdesivir treatment had a significant positive correlation with length of hospital stay. A linear regression model including suPAR, CFR and remdesivir abolished the association of suPAR with length of hospitalisation. Although none of the other clinical variables 
A

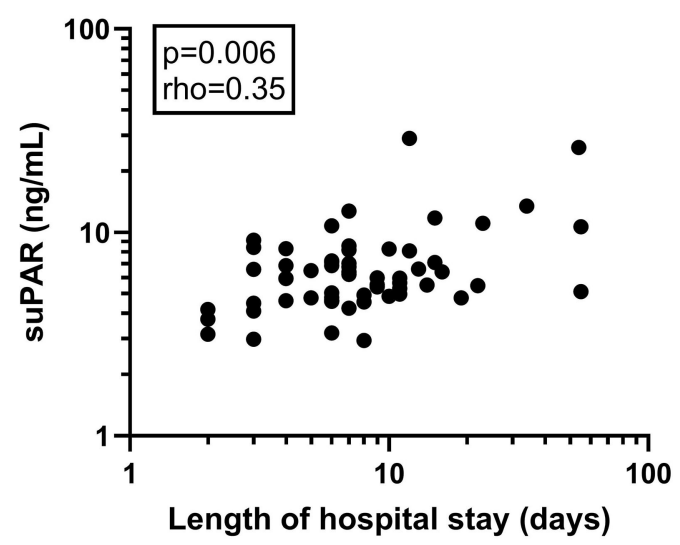

C

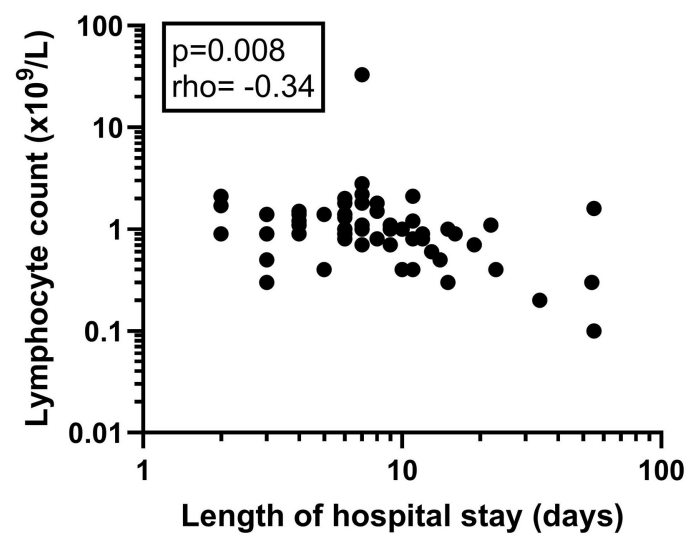

E

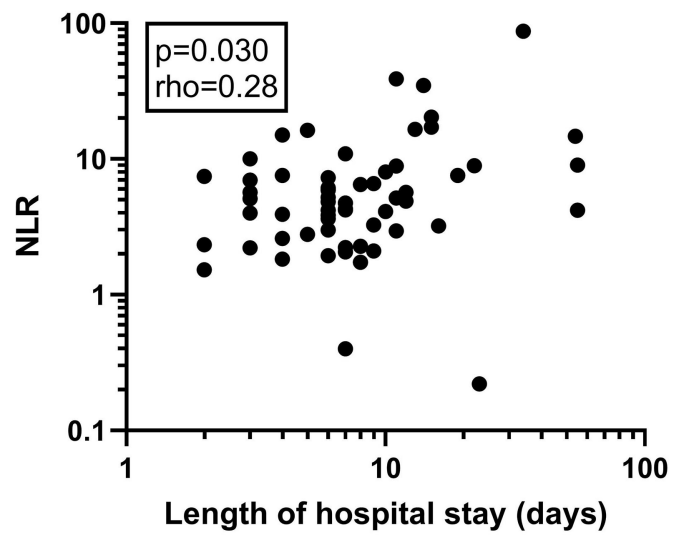

B

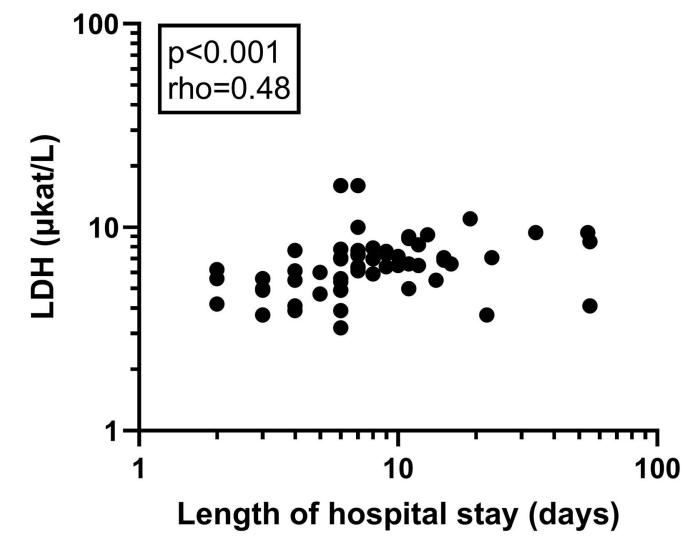

D

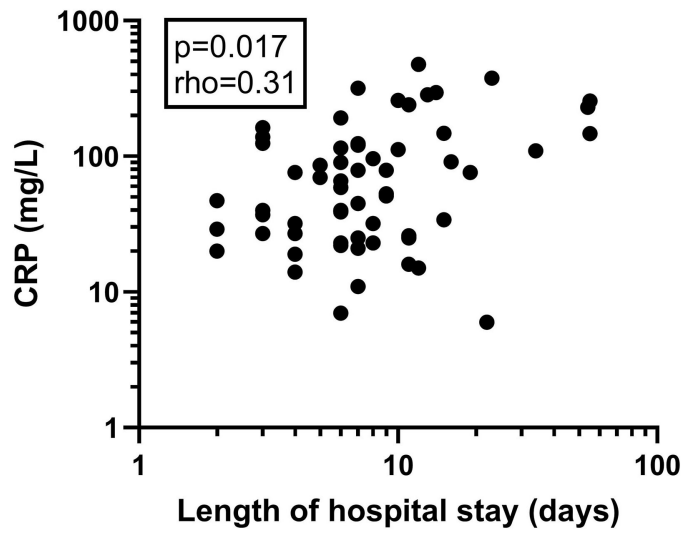

$\mathbf{F}$

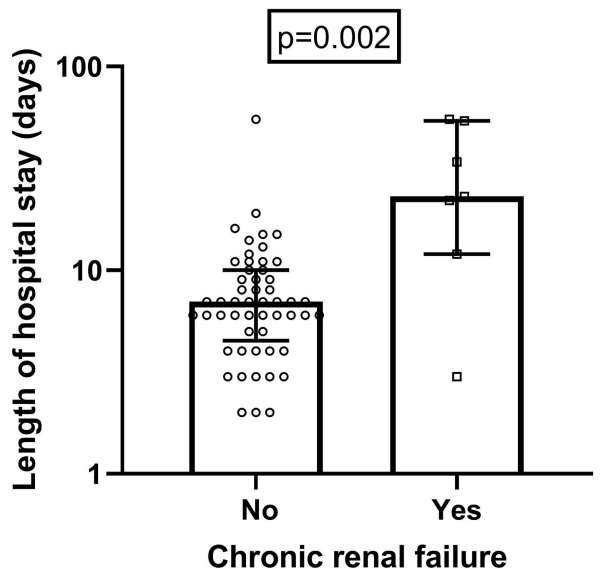

FIGURE 2 | Correlations and associations of biochemical and clinical variables with length of hospital stay. The correlation between the length of the hospital stay and biochemical $(\mathbf{A}-\mathbf{E})$ and clinical variables $\mathbf{( F )}$ were examined. Deceased patients $(n=2)$ were given a fictive length of stay of 55 days to avoid bias. $P$-value and Spearman's correlation coefficient (rho) is given for each correlation analysis. $P$-value from Mann-Whitney U-test is given for CFR. Please observe that axes display a logarithmic scale. suPAR, soluble urokinase plasminogen activator receptor; LDH, lactate dehydrogenase; CRP, C-reactive protein; NLR, neutrophil-to-lymphocyte ratio. 
TABLE 2 | Biochemical variables associated with length of hospital stay (10log) in stepwise linear regression analyses.

\begin{tabular}{|c|c|c|c|}
\hline & $P$-value & $\begin{array}{l}\text { Standardised } \\
\text { beta }\end{array}$ & $\begin{array}{l}\text { Adjusted model } \\
\mathbf{R}^{2}\end{array}$ \\
\hline Model 1 & & & 0.16 \\
\hline suPAR & 0.001 & 0.42 & \\
\hline \multicolumn{4}{|l|}{ Excluded from the model: } \\
\hline \multicolumn{4}{|l|}{ Lactate dehydrogenase } \\
\hline \multicolumn{4}{|l|}{ Lymphocyte count* } \\
\hline \multicolumn{4}{|l|}{ CRP } \\
\hline Model 2 & & & 0.23 \\
\hline suPAR & 0.003 & 0.37 & \\
\hline$N_{L} R^{*}$ & 0.022 & 0.28 & \\
\hline \multicolumn{4}{|l|}{ Excluded from the model: } \\
\hline \multicolumn{4}{|l|}{ Lactate dehydrogenase } \\
\hline CRP & & & \\
\hline
\end{tabular}

sUPAR; soluble urokinase activator receptor, NLR; neutrophil-to-lymphocyte ratio, CRP; $C$-reactive protein. * $L y m p h o c y t e$ count and NLR were tested in separate models because of their interrelationship. were significantly associated with suPAR, age, BMI and male sex are known risk factors of hospitalisation and development of severe COVID-19 (46). Hence, these three variables were tested together with suPAR and NLR but did not remain significant in the stepwise analysis.

COVID-19 severity was also tested together with suPAR to reveal if the association of suPAR and length of hospital stay was dependent on the disease severity. This linear regression analysis revealed that both COVID-19 severity $(P=0.002)$ and suPAR levels $(P=0.013)$ are positively associated with the length of hospital stay.

\section{SuPAR and Its Association With COVID-19 Severity}

The association of suPAR and other biochemical and clinical variables with COVID-19 severity was tested by comparison of the mild/moderate disease group of patients $(n=31)$ with the group of severely/critically ill patients $(n=29)$. suPAR, LDH, NLR, NMR, neutrophil count, and CRP were found to be significantly increased in the severe/critical
A

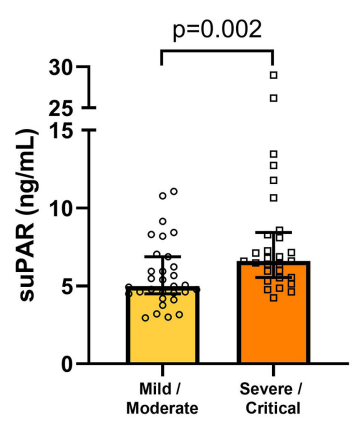

E

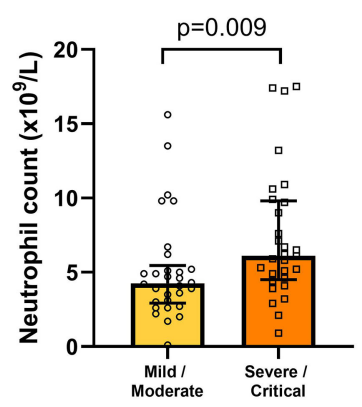

B

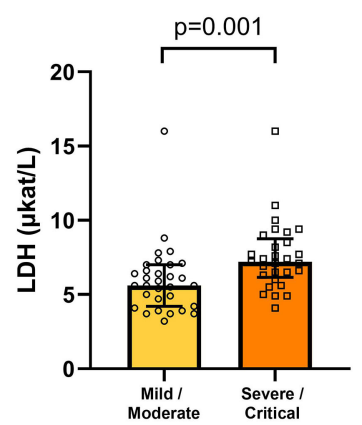

$\mathbf{F}$

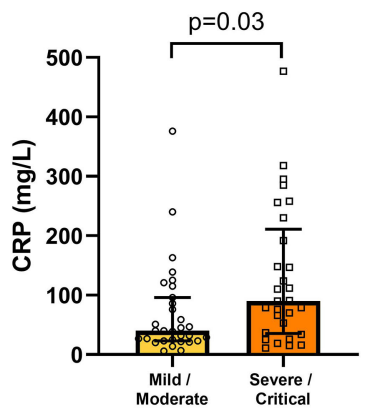

C

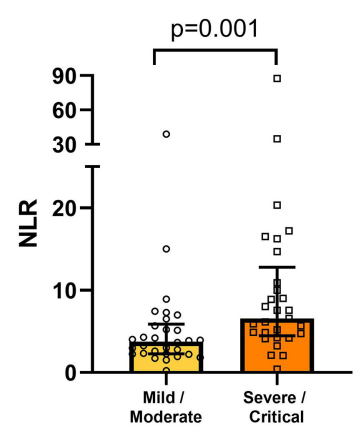

D

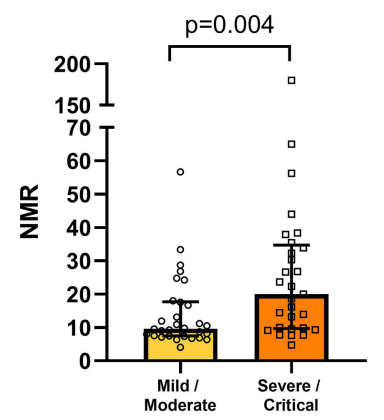

G

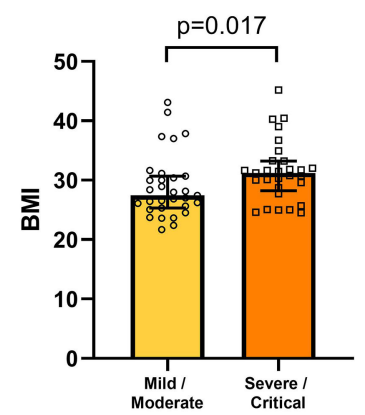

FIGURE 3 | Biochemical (A-F) and clinical (BMl; G) variables, which are significantly increased in COVID-19 patients with severe/critical compared with mild/moderate illness. Bars and error bars represent median values and inter quartile range, respectively. Circles and squares represent individual values. BMI, body mass index; CRP, C-reactive protein; LDH, lactate dehydrogenase; NLR, neutrophil-to-lymphocyte ratio; NMR, neutrophil-to-monocyte ratio; suPAR, soluble urokinase plasminogen activator receptor. 
group of patients, compared with the mild/moderate group (Figures 3A-F). Among clinical variables, only BMI was significantly different between the two severity groups (Figure 3G). Age, symptom duration, haemoglobin, cell counts (platelets, leukocytes, lymphocytes, monocytes, eosinophils, basophils), sodium, potassium, plasma creatinine and eGFR were not significantly different between the two severity groups (not shown).

$\chi^{2}$ tests for binary variables (sex, current/previous smoking status, presence of CVD, chronic pulmonary disease, diabetes, CRF or remdesivir treatment) in relation to COVID-19 severity did not reveal any statistically significant associations. Corticosteroid treated patients were significantly overrepresented in the severe/critical group of patients $(P=$ 0.003 , not shown).

TABLE 3 | Binary logistic regressions for the outcome of severe/critical COVID-19 disease (versus mild/moderate disease).

\begin{tabular}{lcccc}
\hline Model & AUC $(\mathbf{9 5} \% \mathbf{~ C l )}$ & Baseline variable & OR $(\mathbf{9 5} \% \mathbf{~ C l )}$ & $\boldsymbol{P}$-value \\
\hline Only suPAR & $0.73(0.61-0.86)$ & suPAR & $1.35(1.04-1.75)$ & 0.023 \\
Optimised & $0.80(0.69-0.91)$ & sUPAR & $1.42(1.04-1.94)$ & 0.025 \\
& & BMI & $1.16(1.02-1.33)$ & 0.024 \\
& & NLR & $1.11(0.99-1.23)$ & 0.077 \\
& & LDH (excluded) & N/A & N/A
\end{tabular}

\section{Predictors of COVID-19 Severity Evaluated by a Logistic Regression Analysis}

Baseline variables associated with COVID-19 severity were combined in a stepwise logistic regression model (forward: conditional) to evaluate suPAR in relation to the other variables (Table 3). Due to the interrelationship between neutrophil count, NLR and NMR, only NLR was tested together with suPAR, LDH, $\mathrm{CRP}$ and BMI. suPAR levels or predicted probabilities from the optimised regression model were thereafter used to create receiver operator characteristics (ROC) curves for each model, where AUC was calculated (Table 3, Figure 4). An optimal suPAR cut-off at $5.9 \mathrm{ng} / \mathrm{mL}$ was achieved at a specificity of $71 \%$ and a sensitivity of $72 \%$.

\section{SuPAR Based Stratification in Relation to COVID-19 Severity}

Based on previous research (47) and guidelines from the manufacturer of the suPAR ELISA, a suPAR of $<4 \mathrm{ng} / \mathrm{mL}$ supports patient discharge whereas $>6 \mathrm{ng} / \mathrm{mL}$ supports hospitalisation. Hence, our patients were stratified into three groups based on suPAR levels: low $(<4 \mathrm{ng} / \mathrm{m})$, medium (4$6 \mathrm{ng} / \mathrm{mL})$ and high $(>6 \mathrm{ng} / \mathrm{mL})$. The frequency of patients with mild/moderate and severe/critical illness was significantly different between the suPAR stratification groups $(P=0.004)$ with none of the severely/critically ill patients having low suPAR levels (Figure 5). Furthermore, a higher frequency of severely/critically ill patients was found in the group of high

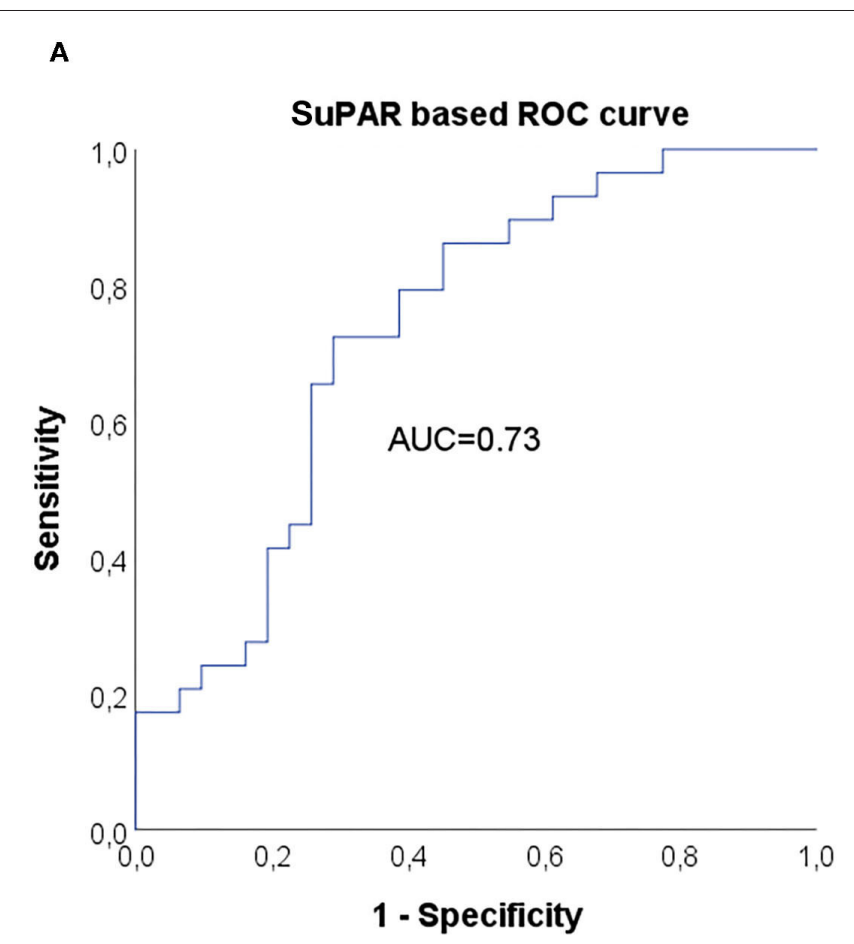

B

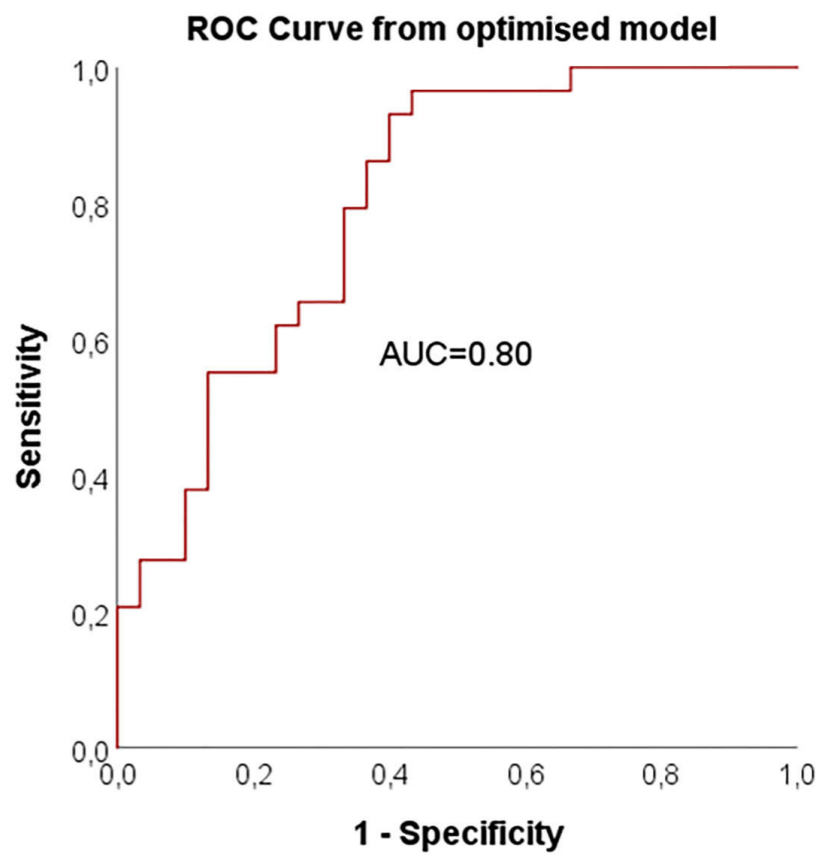

FIGURE 4 | Receiver operating characteristic (ROC) curve and area under curve (AUC) for prediction of COVID-19 severity. AUC for suPAR based prediction of COVID-19 severity (A) and AUC for predicted probabilities from the optimised model with suPAR, BMI and NLR (B). 


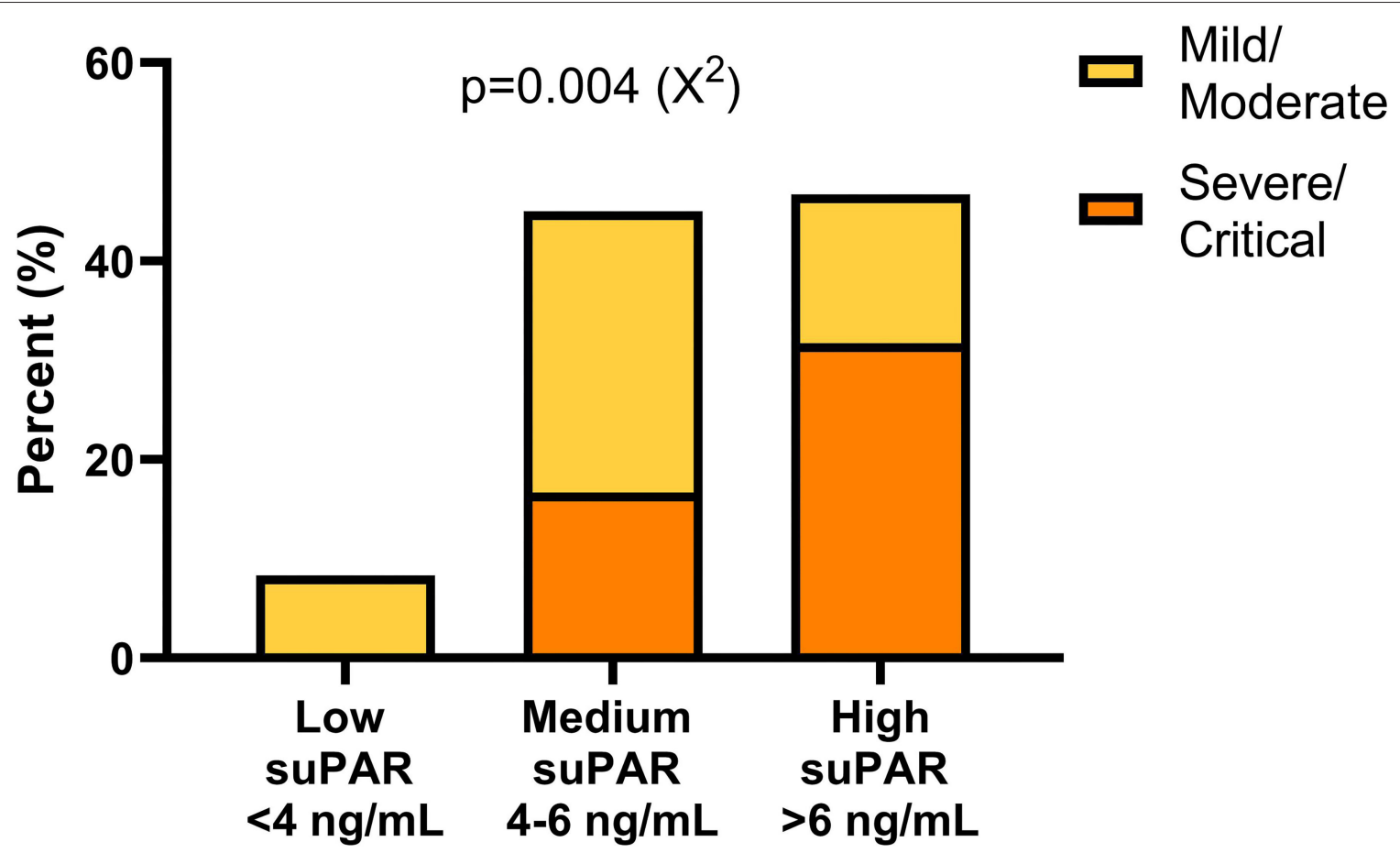

FIGURE 5 | Frequencies of patients with mild/moderate and severe/critical illness within different suPAR level intervals. Patients were stratified into three suPAR level groups according to manufacturer's recommendations. A $\chi^{2}$ test revealed asymmetric distribution of patients with different disease severity. suPAR, soluble urokinase plasminogen activator receptor.

suPAR compared to mild/moderately ill (Figure 5). The two deceased patients had a baseline suPAR within the group of medium and high suPAR levels, respectively.

\section{DISCUSSION}

The present study confirms but also contributes with new knowledge of suPAR as an independent predictor of organ damage, in this case pneumonia with respiratory failure, and length of hospital stay for patients with different severity of COVID-19 in a Swedish setting. suPAR was significantly elevated at inclusion in patients who later developed severe or critical illness with increased oxygen demand and subsequently had a longer stay at the hospital. The length of hospital stay in this cohort of COVID-19 patients was mainly determined by the need for oxygen supplementation with gradual phasing out and not the need for rehabilitation, since rehabilitation primarily was carried out at another department. Our results are consistent with previous studies $(16,47)$, but to our knowledge, suPAR has previously not been shown to independently reflect the cohesive length of hospital stay.

Nevertheless, suPAR has previously been shown to correlate with a prolonged stay at hospital due to other serious conditions with excessive inflammation, such as cardiac surgery, pneumonia in children, and burn injuries (48-50). Besides this, the significance of elevated suPAR levels in viral infections such as human immunodeficiency virus, hepatitis B virus, hepatitis $\mathrm{C}$ virus, and hantavirus, has been established before the SARS-CoV-2 pandemic. Like its importance in COVID-19, elevated suPAR was demonstrated to significantly correlate with severity and mortality in these conditions (51-55).

The concentration of suPAR in sera correlated with the degree of COVID-19 severity, which has been shown previously (47). In SARS-CoV-2 infected individuals with low admission levels of suPAR $(<4 \mathrm{ng} / \mathrm{ml})$, the risk of needing mechanical ventilation and the 14-day mortality was almost non-existent, while levels between $4-6 \mathrm{ng} / \mathrm{ml}$ and especially $>6 \mathrm{ng} / \mathrm{ml}$ were associated with a significantly increased risk. Similar outcomes of stratification of suPAR levels in relation to COVID-19 disease classification were obtained in this study. Interestingly, the cut-off level for severe/critical disease obtained from our study population $(5.9 \mathrm{ng} / \mathrm{mL})$ was very close to the manufacturer's cut-off level for the recommendation of hospitalisation $(6 \mathrm{ng} / \mathrm{mL})$.

The study cohort reflects the well described characteristics of hospitalised patients with COVID-19, with a male dominance, middle-aged and older individuals, presence of co-morbidities such as CVD, chronic pulmonary disease, obesity, and diabetes (56-58). Although these conditions are known risk factors for severe COVID-19, somewhat surprisingly, we did not find a significant association of co-morbidities, besides obesity, with disease severity. This is partly explained by the limited number of patients in each group. Approximately one tenth of the cohort had an immunosuppressive disorder, whereof two patients became critically ill and one with a newly diagnosed haematological malignancy deceased during the hospital stay. These findings are consistent with prior observations indicating a 
relatively low risk, compared to the general population, of severe COVID-19 due to immunosuppression (59-63). However, since not all patients with COVID-19 at the hospital were included in this study, definite conclusions cannot be drawn from the proportion of immunosuppressed relative to immunocompetent patients in the cohort. Most of the patients were classified as moderately to severely ill, i.e., needed non-invasive ventilation support mainly in the form of HFNOT. All of them received dexamethasone to reduce the inflammation in the lungs. Sixty percent of the patients were already prescribed corticosteroids at inclusion, which might have influenced the suPAR levels. In fact, corticosteroids have a suppressive effect on suPAR (21, 64). However, among patients in this study, suPAR levels were higher in corticosteroid treated patients, probably indicating dexamethasone treatment as a surrogate marker of severe disease. Similarly, suPAR levels were higher in patients who received remdesivir at inclusion, reflecting severe inflammation and lung involvement of COVID-19 in these patients already early in the course of the disease. Remdesivir treatment was, however, not associated with disease severity, but rather with length of hospital stay. A similar association was in fact made in studies by Anderson et al. (65) and Spinner et al. (66), in which length of hospital stay was shown to be affected by remdesivir treatment and a peak in discharge rates was observed upon completion of the intravenous therapy, suggesting that physicians actually delayed discharge to complete treatment. The small cohort in this study does not allow any definite conclusions to be drawn regarding possible beneficial effects of remdesivir on disease severity.

The main strengths of the study were the prospective design, the well-characterised patient cohort, and that the assessment of clinical variables and review of medical records in all patients was done by one, experienced infectious disease specialist (J.S.). However, some limitations deserve to be mentioned. The range of symptom duration was wide, explained by the fact that some patients were initially receiving care at another pandemic department at the hospital and were not included until they were transferred to the Department of Infectious Diseases. Many elderly patients were excluded because of acute or chronic cognitive impairment, which resulted in a relatively limited study population. For practical reasons, only Swedish and Englishspeaking patients were included, which might have ruled out patients known to have an increased risk of developing severe COVID-19 $(67,68)$.

\section{CONCLUSIONS}

We show that suPAR is an independent predictor for the development of severe COVID-19 in patients in need of hospital care and supplemental oxygen therapy, and it helps to predict the length of hospital stay and thereby provide support for

\section{REFERENCES}

1. Wang C, Horby PW, Hayden FG, Gao GF. A novel coronavirus outbreak of global health concern. Lancet. (2020) 395:4703. doi: 10.1016/S0140-6736(20)30185-9 prioritisation of the care level before the patient's condition deteriorates. Studies on suPAR kinetics during hospital stay and the effect of immunosuppressive therapies on suPAR levels may further clarify the significance of this biomarker in hospitalised patients with SARS-CoV-2 infection.

\section{DATA AVAILABILITY STATEMENT}

The original contributions presented in the study are included in the article/supplementary material, further inquiries can be directed to the corresponding author.

\section{ETHICS STATEMENT}

The studies involving human participants were reviewed and approved by The Swedish Ethical Review Authority (Decision number 2020-02580). The patients/participants provided their written informed consent to participate in this study.

\section{AUTHOR CONTRIBUTIONS}

HE, CI, AG, ML, Å-A, and JS participated in conception and design of the study. MG and $\mathrm{FH}$ processed serum samples. $\mathrm{HE}$, $\mathrm{CI}, \mathrm{AG}$, and JS took part in acquisition, analysis or interpretation of the data. HE, CI, AG, MG, FH, ML, AN-A, and JS were involved in writing and critiquing of drafts of the manuscript. HE, CI, AG, MG, FH, ML, Å-A, and JS approved the final manuscript for submission. All authors contributed to the article and approved the submitted version.

\section{FUNDING}

This study was supported by Region Östergötland (Stiftelseförvaltningen, RÖ-931742 (HE); ALF Grant, RÖ935411 (JS); Regional ALF Grant 2021 (ÅN-A and JS), Vrinnevi Hospital in Norrköping) and SciLifeLab/KAW COVID-19 Research Program (ML).

\section{ACKNOWLEDGMENTS}

We wish to express our gratitude to the cooperative staff at the Departments of Infectious Diseases, Haematology, Nephrology, Renal dialysis, Urology, Surgery, Pandemic Ward 99, Intensive Care, and the Clinical Chemistry Laboratory, Vrinnevi Hospital, Norrköping, Sweden, and all the study participants for their efforts. Johan Nordgren and co-workers at the Division of Molecular Medicine and Virology, Linköping University, Sweden, are acknowledged for the SARS-CoV-2 PCR assays in the controls. We also wish to thank Forum Östergötland, Region Östergötland, Sweden, for careful review of the study protocol.

2. Hu B, Guo H, Zhou P, Shi ZL. Characteristics of SARS-CoV-2 and COVID-19. Nat Rev Microbiol. (2021) 19:141-54. doi: 10.1038/s41579-020-00459-7

3. Organisation WH. Weekly Operational Update on COVID-19. Available online at: https://wwwwhoint/publications/m/item/weekly-operationalupdate-on-covid-19-\$-\$16-august-2021. 
4. Zhou F, Yu T, Du R, Fan G, Liu Y, Liu Z, et al. Clinical course and risk factors for mortality of adult inpatients with COVID-19 in Wuhan, China: a retrospective cohort study. Lancet. (2020) 395:105462. doi: 10.1016/S0140-6736(20)30566-3

5. Goyal P, Choi JJ, Pinheiro LC, Schenck EJ, Chen R, Jabri A, et al. Clinical characteristics of Covid-19 in New York City. N Engl J Med. (2020) 382:23724. doi: 10.1056/NEJMc2010419

6. Jain V, Yuan JM. Predictive symptoms and comorbidities for severe COVID19 and intensive care unit admission: a systematic review and meta-analysis. Int J Public Health. (2020) 65:533-46. doi: 10.1007/s00038-020-01390-7

7. Soraya GV, Ulhaq ZS. Crucial laboratory parameters in COVID-19 diagnosis and prognosis: an updated meta-analysis. Med Clin. (2020) 155:14351. doi: 10.1016/j.medcli.2020.05.017

8. Gao Y, Li T, Han M, Li X, Wu D, Xu Y, et al. Diagnostic utility of clinical laboratory data determinations for patients with the severe COVID-19. J Med Virol. (2020) 92:791-6. doi: 10.1002/jmv.25770

9. Kerget B, Kerget F, Aksakal A, Askin S, Ucar EY, Saglam L. Evaluation of the relationship between KIM-1 and suPAR levels and clinical severity in COVID-19 patients: a different perspective on suPAR. J Med Virol. (2021) 93:5568-73. doi: 10.1002/jmv.27099

10. Huang M, Li L, Shen J, Wang Y, Wang R, Yuan C, et al. Plasma levels of the active form of suPAR are associated with COVID-19 severity. Crit Care. (2020) 24:704. doi: 10.1186/s13054-020-03336-0

11. Arnold DT, Attwood M, Barratt S, Morley A, Elvers KT, McKernon $\mathrm{J}$, et al. Predicting outcomes of COVID-19 from admission biomarkers: a prospective UK cohort study. Emerg Med J. (2021) 38:543-8. doi: 10.1136/emermed-2020-210380

12. Oulhaj A, Alsuwaidi AR, Suliman A, Gasmelseed H, Khan S, Alawi S, et al. Admission levels of Soluble Urokinase Plasminogen Activator Receptor (suPAR) are associated with the development of severe complications in hospitalised COVID-19 patients: a prospective cohort study. Int J Infect Dis. (2021) 107:188-94. doi: 10.1016/j.ijid.2021.04.026

13. Chalkias A, Mouzarou A, Samara E, Xanthos T, Ischaki E, Pantazopoulos I. Soluble urokinase plasminogen activator receptor: a biomarker for predicting complications and critical care admission of COVID-19 patients. Mol Diagn Ther. (2020) 24:517-21. doi: 10.1007/s40291-020-00481-8

14. Keskinidou C, Vassiliou AG, Zacharis A, Jahaj E, Gallos P, Dimopoulou I, et al. Endothelial, immunothrombotic, and inflammatory biomarkers in the risk of mortality in critically ill COVID-19 patients: the role of dexamethasone. Diagnostics. (2021) 11:1249. doi: 10.3390/diagnostics11071249

15. Velissaris D, Lagadinou M, Paraskevas T, Oikonomou E, Karamouzos V, Karteri S, et al. Evaluation of plasma soluble urokinase plasminogen activator receptor levels in patients with COVID-19 and non-COVID-19 pneumonia: an observational cohort study. J Clin Med Res. (2021) 13:4748. doi: 10.14740/jocmr4579

16. Rovina N, Akinosoglou K, Eugen-Olsen J, Hayek S, Reiser J, GiamarellosBourboulis EJ. Soluble urokinase plasminogen activator receptor (suPAR) as an early predictor of severe respiratory failure in patients with COVID-19 pneumonia. Crit Care. (2020) 24:187. doi: 10.1186/s13054-020-02897-4

17. Azam TU, Shadid HR, Blakely P, O'Hayer P, Berlin H, Pan M, et al. Soluble Urokinase Receptor (SuPAR) in COVID-19-Related AKI. J Am Soc Nephrol JASN. (2020) 31:2725-35. doi: 10.1681/ASN.2020060829

18. Plesner T, Behrendt N, Ploug M. Structure, function and expression on blood and bone marrow cells of the urokinase-type plasminogen activator receptor, uPAR. Stem Cells. (1997) 15:398-408. doi: 10.1002/stem.150398

19. Plesner T, Ralfkiaer E, Wittrup M, Johnsen H, Pyke C, Pedersen TL, et al. Expression of the receptor for urokinase-type plasminogen activator in normal and neoplastic blood cells and hematopoietic tissue. Am J Clin Pathol. (1994) 102:835-41. doi: 10.1093/ajcp/102.6.835

20. Smith HW, Marshall CJ. Regulation of cell signalling by uPAR. Nat Rev Molec Cell Biol. (2010) 11:23-36. doi: 10.1038/nrm2821

21. Hartmann Rasmussen L, Vang Petersen JE, Eugen-Olsen J. Soluble urokinase plasminogen activator receptor (suPAR) as a biomarker of systemic chronic inflammation. Front Immunol. (2021) 10:e036125. doi: 10.1136/bmjopen-2019-036125

22. Rolff HC, Christensen IJ, Svendsen LB, Wilhelmsen M, Lund IK, Thurison T, et al. The concentration of the cleaved suPAR forms in pre- and postoperative plasma samples improves the prediction of survival in colorectal cancer: a nationwide multicenter validation and discovery study. J Surg Oncol. (2019) 120:1404-11. doi: 10.1002/jso.25733

23. Aronen A, Aittoniemi J, Huttunen R, Nikkola A, Rinta-Kiikka I, Nikkola $\mathrm{J}$, et al. Plasma suPAR may help to distinguish between chronic pancreatitis and pancreatic cancer. Scand J Gastroenterol. (2021) 56:815. doi: 10.1080/00365521.2020.1849383

24. Ozdirik B, Stueven A, Knorr J, Geisler L, Mohr R, Demir M, et al. Soluble urokinase plasminogen activator receptor (suPAR) concentrations are elevated in patients with neuroendocrine malignancies. J Clin Med. (2020) 9:1647. doi: 10.3390/jcm9061647

25. Loosen SH, Breuer A, Tacke F, Kather JN, Gorgulho J, Alizai PH, et al. Circulating levels of soluble urokinase plasminogen activator receptor predict outcome after resection of biliary tract cancer. JHEP Rep. (2020) 2:100080. doi: 10.1016/j.jhepr.2020.100080

26. Liu KL, Fan JH, Wu J. Prognostic role of circulating soluble uPAR in various cancers: a systematic review and meta-analysis. Clin Lab. (2017) 63:87180. doi: 10.7754/Clin.Lab.2017.170110

27. Enocsson H, Sjöwall C, Wetterö J. Soluble urokinase plasminogen activator receptor-a valuable biomarker in systemic lupus erythematosus? Clin Chim Acta. (2015) 444:234-41. doi: 10.1016/j.cca.2015.02.031

28. Enocsson H, Wirestam L, Dahle C, Padyukov L, Jonsen A, Urowitz MB, et al. Soluble urokinase plasminogen activator receptor (suPAR) levels predict damage accrual in patients with recent-onset systemic lupus erythematosus. $J$ Autoimmun. (2020) 106:102340. doi: 10.1016/j.jaut.2019.102340

29. Enocsson H, Wetterö J, Skogh T, Sjöwall C. Soluble urokinase plasminogen activator receptor levels reflect organ damage in systemic lupus erythematosus. Transl Res J Lab Clin Med. (2013) 162:287-96. doi: 10.1016/j.trsl.2013.07.003

30. Enocsson H, Lukic T, Ziegelasch M, Kastbom A. Serum levels of the soluble urokinase plasminogen activator receptor (suPAR) correlates with disease activity in early rheumatoid arthritis and reflects joint damage over time. Transl Res J Lab Clin Med. (2021) 232:142-9. doi: 10.1016/j.trsl.2021. 02.007

31. Schneider UV, Nielsen RL, Pedersen C, Eugen-Olsen J. The prognostic value of the suPARnostic ELISA in HIV-1 infected individuals is not affected by uPAR promoter polymorphisms. BMC Infect Dis. (2007) 7:134. doi: 10.1186/1471-2334-7-134

32. Ostrowski SR, Ullum H, Goka BQ, Hoyer-Hansen G, Obeng-Adjei G, Pedersen BK, et al. Plasma concentrations of soluble urokinase-type plasminogen activator receptor are increased in patients with malaria and are associated with a poor clinical or a fatal outcome. J Infect Dis. (2005) 191:1331-41. doi: 10.1086/428854

33. Huang Q, Xiong H, Yan P, Shuai T, Liu J, Zhu L, et al. The diagnostic and prognostic value of suPAR in patients with sepsis: a systematic review and meta-analysis. Shock. (2020) 53:416-25. doi: 10.1097/SHK.0000000000001434

34. Ni W, Han Y, Zhao J, Cui J, Wang K, Wang R, et al. Serum soluble urokinasetype plasminogen activator receptor as a biological marker of bacterial infection in adults: a systematic review and meta-analysis. Sci Rep. (2016) 6:39481. doi: 10.1038/srep39481

35. Schulman H, Niward K, Abate E, Idh J, Axenram P, Bornefall A, et al. Sedimentation rate and suPAR in relation to disease activity and mortality in patients with tuberculosis. Int J Tuberc Lung Dis. (2019) 23:115561. doi: 10.5588/ijtld.18.0634

36. Lin MF, Sun B, Liu ZY, Tang P, Zhang LJ, Wang YY. Evaluation of the clinical diagnostic value of traditional inflammatory markers and novel biomarkers in intracellular bacterial bloodstream infections. Cytokine. (2020) 136:155238. doi: 10.1016/j.cyto.2020.155238

37. Loonen AJM, Kesarsing C, Kusters R, Hilbink M, Wever PC, van den Brule AJC. High pneumococcal DNA load, procalcitonin and suPAR levels correlate to severe disease development in patients with pneumococcal pneumonia. Eur J Clin Microbiol Infect Dis. (2017) 36:1541-7. doi: 10.1007/s10096-017-2963-2

38. Lafon T, Cazalis MA, Vallejo C, Tazarourte K, Blein S, Pachot A, et al. Prognostic performance of endothelial biomarkers to early predict clinical deterioration of patients with suspected bacterial infection and sepsis admitted to the emergency department. Ann Intensive Care. (2020) 10:113. doi: 10.1186/s13613-020-00729-w

39. Velissaris D, Dimopoulos G, Parissis J, Alexiou Z, Antonakos N, Babalis D, et al. Prognostic role of soluble urokinase plasminogen activator receptor 
at the emergency department: a position paper by the Hellenic sepsis study group. Infect Dis Ther. (2020) 9:407-16. doi: 10.1007/s40121-020-00301-w

40. Schultz M, Rasmussen LJH, Hoi-Hansen T, Kjoller E, Jensen BN, Lind MN, et al. Early discharge from the emergency department based on soluble urokinase plasminogen activator receptor (suPAR) levels: a TRIAGE III substudy. Dis Markers. (2019) 2019:3403549. doi: 10.1155/2019/3403549

41. Kumar P, Kakar A, Gogia A, Waziri N. Evaluation of soluble urokinasetype plasminogen activator receptor (suPAR) quick test for triage in the emergency department. J Family Med Prim Care. (2019) 8:38715. doi: 10.4103/jfmpc.jfmpc_116_19

42. Rasmussen LJ, Ladelund S, Haupt TH, Ellekilde G, Poulsen JH, Iversen $\mathrm{K}$, et al. Soluble urokinase plasminogen activator receptor (suPAR) in acute care: a strong marker of disease presence and severity, readmission and mortality. A retrospective cohort study. Emerg Med J. (2016) 33:76975. doi: 10.1136/emermed-2015-205444

43. Saguti F, Magnil E, Enache L, Churqui MP, Johansson A, Lumley $\mathrm{D}$, et al. Surveillance of wastewater revealed peaks of SARS-CoV-2 preceding those of hospitalized patients with COVID-19. Water Res. (2021) 189:116620. doi: 10.1016/j.watres.2020.116620

44. Health NIo. NIH. treatment guidelines: Clinical Spectrum of SARS-CoV-2 Infection. Available online at: https://filescovid19treatmentguidelinesnihgov/ guidelines/section/section_43pdf. (2021).

45. Levey AS, Coresh J, Greene T, Stevens LA, Zhang YL, Hendriksen S, et al. Using standardized serum creatinine values in the modification of diet in renal disease study equation for estimating glomerular filtration rate. Ann Intern Med. (2006) 145:247-54. doi: 10.7326/0003-4819-145-4-200608150-00004

46. Ando $\mathrm{W}$, Horii $\mathrm{T}$, Uematsu $\mathrm{T}$, Hanaki H, Atsuda $\mathrm{K}$, Otori $\mathrm{K}$. Impact of overlapping risks of type 2 diabetes and obesity on coronavirus disease severity in the United States. Sci Rep. (2021) 11:17968. doi: 10.1038/s41598-021-96720-x

47. Altintas I, Eugen-Olsen J, Seppala S, Tingleff J, Stauning MA, El Caidi NO, et al. suPAR Cut-Offs for risk stratification in patients with symptoms of COVID-19. Biomark Insights. (2021) 16:11772719211034685. doi: 10.1177/11772719211034685

48. Schultz-Swarthfigure CT, McCall P, Docking R, Galley HF, Shelley B. Can soluble urokinase plasminogen receptor predict outcomes after cardiac surgery? Interact Cardiovasc Thorac Surg. (2021) 32:236-43. doi: 10.1093/icvts/ivaa239

49. Wrotek A, Jackowska T, Pawlik K. Soluble urokinase plasminogen activator receptor: an indicator of pneumonia severity in children. Adv Exp Med Biol. (2015) 835:1-7. doi: 10.1007/5584_2014_40

50. Backes Y, van der Sluijs KF, Tuip de. Boer AM, Hofstra JJ, Vlaar AP, Determann RM, et al. Soluble urokinase-type plasminogen activator receptor levels in patients with burn injuries and inhalation trauma requiring mechanical ventilation: an observational cohort study. Crit Care. (2011) 15:R270. doi: 10.1186/cc10550

51. Hoenigl M, Moser CB, Funderburg N, Bosch R, Kantor A, Zhang Y, et al. Soluble urokinase plasminogen activator receptor is predictive of non-AIDS events during antiretroviral therapy-mediated viral suppression. Clin Infect Dis. (2019) 69:676-86. doi: 10.1093/cid/ciy966

52. Huang Z, Wang N, Huang S, Chen Y, Yang S, Gan Q, et al. Increased serum soluble urokinase plasminogen activator receptor predicts short-term outcome in patients with hepatitis B-related acute-on-chronic liver failure. Gastroenterol Res Pract. (2019) 2019:3467690. doi: 10.1155/2019/3467690

53. Berres ML, Schlosser B, Berg T, Trautwein C, Wasmuth HE. Soluble urokinase plasminogen activator receptor is associated with progressive liver fibrosis in hepatitis C infection. J Clin Gastroenterol. (2012) 46:3348. doi: 10.1097/MCG.0b013e31822da19d

54. Sidenius N, Sier CF, Ullum H, Pedersen BK, Lepri AC, Blasi F, et al. Serum level of soluble urokinase-type plasminogen activator receptor is a strong and independent predictor of survival in human immunodeficiency virus infection. Blood. (2000) 96:4091-5. doi: 10.1182/blood.V96.13.4091

55. Outinen TK, Tervo L, Makela S, Huttunen R, Maenpaa N, Huhtala H, et al. Plasma levels of soluble urokinase-type plasminogen activator receptor associate with the clinical severity of acute Puumala hantavirus infection. PLoS One. (2013) 8:e71335. doi: 10.1371/journal.pone.0071335

56. Asleh R, Asher E, Yagel O, Samuel T, Elbaz-Greener G, Wolak A, et al. Predictors of hypoxemia and related adverse outcomes in patients hospitalized with COVID-19: a double-center retrospective study. J Clin Med. (2021) 10:3581. doi: $10.3390 / \mathrm{jcm} 10163581$

57. Turan O, Mirici A, Duru Akcali S, Turan PA, Batum O, Sengul A, et al. Characteristics of Hospitalized COVID-19 Patients and Parameters Associated with Severe Pneumonia. Int J Clin Pract. (2021) 75:e14786. doi: 10.1111/ijcp.14786

58. Signes-Costa J, Nunez-Gil IJ, Soriano JB, Arroyo-Espliguero R, Eid CM, Romero R, et al. Prevalence and 30-day mortality in hospitalized patients with Covid-19 and prior lung diseases. Arch Bronconeumol. (2021) 57:1320. doi: 10.1016/j.arbres.2020.11.012

59. Tassone D, Thompson A, Connell $\mathrm{W}$, Lee $\mathrm{T}$, Ungaro $\mathrm{R}$, An P, et al. Immunosuppression as a risk factor for COVID-19: a meta-analysis. Intern Med J. (2021) 51:199-205. doi: 10.1111/imj.15142

60. Bsteh G, Assar H, Hegen H, Heschl B, Leutmezer F, Di Pauli F, et al. COVID-19 severity and mortality in multiple sclerosis are not associated with immunotherapy: Insights from a nation-wide Austrian registry. PLoS One. (2021) 16:e255316. doi: 10.1371/journal.pone.0255316

61. Cajamarca-Baron J, Guavita-Navarro D, Buitrago-Bohorquez J, GallegoCardona L, Navas A, Cubides H, et al. SARS-CoV-2 (COVID-19) in patients with some degree of immunosuppression. Reumatol Clin (Engl Ed). (2021) 17:408-19. doi: 10.1016/j.reumae.2020.08.001

62. Sjowall J, Azharuddin M, Frodlund M, Zhang Y, Sandner L, Dahle C, et al. SARS-CoV-2 Antibody isotypes in systemic lupus erythematosus patients prior to vaccination: associations with disease activity, antinuclear antibodies, and immunomodulatory drugs during the first year of the pandemic. Front Immunol. (2021) 12:724047. doi: 10.3389/fimmu.2021.724047

63. Bower H, Frisell T, Di Giuseppe D, Delcoigne B, Ahlenius GM, Baecklund $\mathrm{E}$, et al. Impact of the COVID-19 pandemic on morbidity and mortality in patients with inflammatory joint diseases and in the general population: a nationwide Swedish cohort study. Ann Rheum Dis. (2021) 80:108693. doi: 10.1136/annrheumdis-2021-219845

64. Kolho KL, Valtonen E, Rintamaki H, Savilahti E. Soluble urokinase plasminogen activator receptor suPAR as a marker for inflammation in pediatric inflammatory bowel disease. Scand J Gastroenterol. (2012) 47:9515. doi: 10.3109/00365521.2012.699549

65. Anderson MR, Bach PB, Baldwin MR. Hospital Length of Stay for Patients with Severe COVID-19: implications for Remdesivir's Value. Pharmacoecon Open. (2021) 5:129-31. doi: 10.1007/s41669-020-00243-6

66. Spinner CD, Gottlieb RL, Criner GJ, Arribas Lopez JR, Cattelan AM, Soriano Viladomiu A, et al. Effect of remdesivir vs standard care on clinical status at 11 days in patients with moderate COVID-19: a randomized clinical trial. JAMA. (2020) 324:1048-57. doi: 10.1001/jama.2020.16349

67. Hollis ND Li W, Van Dyke ME, Njie GJ, Scobie HM, Parker EM, et al. Racial and ethnic disparities in incidence of SARS-CoV-2 infection, 22 US States and DC, January 1-October 1, 2020. Emerg Infect Dis. (2021) 27:147781. doi: $10.3201 /$ eid2705.204523

68. Ebinger JE, Driver M, Ji H, Claggett B, Wu M, Luong E, et al. Temporal variations in the severity of COVID-19 illness by race and ethnicity. BMJ Nutr Prev Health. (2021) 4:166-73. doi: 10.1136/bmjnph-2021-000253

Conflict of Interest: The authors declare that the research was conducted in the absence of any commercial or financial relationships that could be construed as a potential conflict of interest.

Publisher's Note: All claims expressed in this article are solely those of the authors and do not necessarily represent those of their affiliated organizations, or those of the publisher, the editors and the reviewers. Any product that may be evaluated in this article, or claim that may be made by its manufacturer, is not guaranteed or endorsed by the publisher.

Copyright (C) 2021 Enocsson, Idoff, Gustafsson, Govender, Hopkins, Larsson, Nilsdotter-Augustinsson and Sjöwall. This is an open-access article distributed under the terms of the Creative Commons Attribution License (CC BY). The use, distribution or reproduction in other forums is permitted, provided the original author(s) and the copyright owner(s) are credited and that the original publication in this journal is cited, in accordance with accepted academic practice. No use, distribution or reproduction is permitted which does not comply with these terms. 